\title{
Peertechz
}

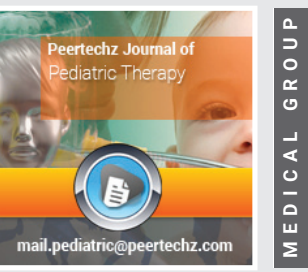

\section{Cardio-metabolic risk}

\section{stratification and life style}

\section{interventions for risk}

\section{reduction among overweight and obese school children}

\author{
Shardul Kamale ${ }^{1}$ Ipseeta Ray Mohanty2*, Vijay Kamale ${ }^{3}$, \\ Nimain Mohanty ${ }^{3}$ and Sabita Dash Mishra ${ }^{4}$ \\ 13rd Year MBBS student, Department of Pharmacology, MGM Medical College, Kamothe, Navi Mumbai, \\ Maharasthra, 410209, India \\ ${ }^{2}$ Professor, Department of Pharmacology, MGM Medical College Kamothe, Navi Mumbai, Maharasthra \\ 410209, India \\ ${ }^{3}$ Department of Pediatrics, MGM Medical College, Navi Mumbai, India \\ ${ }^{4}$ MGM Primary and Secondary School, Nerul, Navi Mumbai, India
}

Received: 20 April, 2020

Accepted: 18 July, 2020

Published: 20 July, 2020

*Corresponding author: Dr. Ipseeta Ray Mohanty Professor, Department of Pharmacology, MGM Medical College Kamothe, Navi Mumbai, Maharasthra 410209, India, E-mail: ipseetamohanty@yahoo.co.in

https://www.peertechz.com

Check for updates

\begin{abstract}
Background and Objectives: Childhood obesity strongly correlates with risk of developing type 2 diabetes and cardiovascular disease in the future. Screening of school children for diabetes and cardiovascular disease risk will be effective in identifying children at risk of developing cardio metabolic diseases and successfully enrolling them in a lifestyle modification program.

Methodology: School children in the age group of 10-18 years were screened using BMI as a determining tool for obesity. The Healthy Heart Score for CVD risk prediction and Indian Diabetes Risk Score (IDRS) were used to categorize the obese and overweight children as having high, medium and low CVD and diabetes risk. The participants were imparted educational intervention based on WHO CVD Risk Reduction Guidelines and the impact of structured educational intervention was assessed.

Results: In the present study, out of the 305 children who were screened, $10.16 \%$ were found to be overweight and $3.93 \%$ were obese. Maximum proportion of overweight children fell under the moderate risk of developing diabetes (68.2\%) category whereas proportion of obese children with moderate and high diabetes risk was found to be $44.4 \%$ and $55.5 \%$ respectively. In addition, it was observed that $31.2 \%$ of overweight children had moderate CVD risk and $68.2 \%$ had high CVD risk. Among the obese children, $11.1 \%$ were stratified as having moderate CVD risk and $88.9 \%$ as high CVD risk. Structured educational intervention resulted in a significant increase in knowledge regarding preventive Strategies for Cardio-metabolic risk modification.
\end{abstract}

Conclusion: $74.2 \%$ and $35.5 \%$ of obese and overweight children were stratified as having high CVD risk and diabetes risk respectively. Educational Intervention resulted in a significant increase in knowledge regarding preventive strategies for CVD and Diabetes Risk \{related to weight control, salt intake, saturated fat restriction, physical activity, maintaining blood pressure\} among obese or overweight children.

\section{Introduction}

The American Diabetes Association (ADA) guidelines indicate that children who are above the $85^{\text {th }}$ percentile for age and gender with additional risk factors should be screened for diabetes [1]. Overweight and obese adolescents with type 2 diabetes are at risk of developing heart disease and other diabetes related complications before the age of 35 years [2]. The prevalence of Cardio-metabolic risk factors in many children has increased substantially over the last 15 years, 
and a study conducted in South India has shown that $68 \%$ of children have at least one elevated risk factor [3]. Clustering of these risk factors will result in enormous personal, societal, and economic costs for many decades. Strategies to address this problem are needed immediately, as prevention of cardiometabolic disorder is far preferable to treatment [4].

Presence of cardiovascular risk factors in youth is known to be associated with the extent of arterial wall damage and intima-media thickness [5]. Given that many cardio-metabolic risk factors track through adolescence and into adulthood, it is vital that these risks be assessed as children progress through puberty and into early adulthood $[6,7]$. Thus, assessment and modulation of CVD risk factors during childhood is essential. Further, there is a need for effective interventions that target reduction of cardio-metabolic risk factor levels beginning at an early age.

Hypertension and Obesity in Youth (AHOY) recently emphasized that besides clinical set up, schools were important stakeholders in population-based health promotion and risk-reduction efforts [8]. The primary objective of the study was to assess the cardiometabolic risk among school children using standardized non-invasive tools. Our central hypothesis is that screening and recruitment will be effective in identifying children at high risk for cardio metabolic diseases and successfully enrolling them in a lifestyle modification program. To accomplish this objective, validated non-invasive tools to assess cardiovascular risk (the Healthy Heart Score) [4] and diabetes risk (Indian Diabetes Risk score) [1], score were used in present study to stratify the cardio metabolic risk among the children. The impact of life style intervention on the knowledge regarding preventive strategies for cardio metabolic risk reduction (Diet and Physical Activity, Weight control) was also delineated.

\section{Materials and Methods}

Approval from the Institutional Ethics Committee was obtained before initiating the study (N-EC/2019/04/49).

Study design: Prospective, Interventional type of study

\section{Study site: MGM School, Nerul, Navi Mumbai}

Sample size: Three hundred and five (305) children were screened to identify overweight and obese children.

Study conducted by Pawar, et al. demonstrates the prevalence of overweight and obesity among South Mumbai children as $17.5 \%$ and $7.8 \%$ respectively [9].

Assumptions: Educational intervention study prior data indicates that difference in the response of matched pairs is normally distributed with standard deviation 4 . If the true difference in the mean response of matched pairs is 2.25 , we will need to study 30 obese and overweight children to be able to reject the null hypothesis that this response difference is zero with probability (power) 0.9. The Type I error probability associated with this test of this null hypothesis is 0.05 .
Study population: Children who conform to the specified Inclusion and Exclusion Criteria were enrolled for the study.

\section{- Inclusion criteriaAge $\geq 10$ years of age}

- Obese and overweight children (Age specific BMI cutoff values corresponding to Adult equivalent BMI of 23 and $28 \mathrm{~kg} / \mathrm{m}^{2}$, Khadilkar, et al. 2002) [10].

- Children and whose parents agreed to sign the informed consent form.

\section{Exclusion criteria}

- More than 18 years

\section{Case Record Form (CRF)}

A CRF was prepared to record the following information of the school children

1. Demographic profile: Age, Gender

2. Anthropometry: BMI and waist Circumference.

3. Lifestyle

- Physical activity: refers to the previous 7-days and required children to recall, activities that they participated in over the previous week [11].

- Dietary habits: The children were required to recall previous 7-days dietary habits.

4. Cardiovascular fitness: The test begins with children running $20-\mathrm{m}$ laps at $8.5 \mathrm{kmph}$. Running speed increases by $0.5 \mathrm{kmph}$ after each 1 -min stage. Children continue running until they can no longer maintain the pace. The test has been shown to be a valid and reliable measure of cardiovascular fitness in children [12].

5. Blood pressure: A systolic and diastolic blood pressure was recorded using sphygmomanometer.

6. Healthy heart score for assessment of CVD risk: Thus, Healthy Heart Scores could range between 5and 18 with lower scores representing a more favourable CVD risk factor profile (Low CVD risk (Score less than 5), Moderate CVD risk (Score between 6-10) and High CVD risk (Score between 11-14).

Scoring: SBP and DBP score $1 \leq 75$ th percentile, score $2=76^{\text {th }}-85^{\text {th }}$ percentile, score $3=86^{\text {th }}-95^{\text {th }}$ percentile and score $4 \geq 95$ th percentile; BMI $>95$ th percentile (score 4 ) and overweight as BMI between $85^{\text {th }}-95^{\text {th }}$ percentile (score 3 ), $75^{-}$ 85th percentile (score 2 ) and BMI <75th percentile (score 1 ). Physical activity > $60 \mathrm{~min}$ (score 1$), 30-60 \mathrm{~min}$ (score 2 ), < $30 \mathrm{~min}$ (score 3). Cardiac fitness (No of $20 \mathrm{~m}$ laps completed) above (score 1), within (score 2) or below (score 3) criterion based age and sex appropriate values.

7. Assessment of diabetes risk: Indian diabetes risk score tool was used to assess the risk of development of diabetes among school children based on their Age, abdominal Obesity, Physical activity and family history of diabetes. 
Scoring: Risk Interpretation as high, moderate and low risk if their IDRS score is $\geq 60,30-50$ and $<30$ respectively. Children having scores $<30$ fell under low diabetes risk category, between $30-50$ as moderate risk and $>60$ as high diabetes risk category.

8. Study procedure: School children between the age of 10 to 18 years were screened to identify the overweight and obese children who were enrolled for the study after taking written informed consent from their parents. Assent was also taken from the children. Subsequently the parameters mentioned on the CRF were filled up. The Healthy Heart Score and diabetes risk score for assessment of cardio-metabolic risk was used to stratify the overweight and obese children into risk categories (low, moderate, high). The children's baseline knowledge on preventive Strategies for cardio metabolic risk modification were scored. Subsequently, the children were counseled on preventive strategies for cardio-metabolic Risk Reduction and thereafter re-administered the same questionnaire to assess the impact of educational intervention.

\section{Data analysis and statistical methods}

SPSS software was used to summarize the children's survey responses. Mean + SD was used to summarize the study results. Student $\mathrm{t}$ test was used to compare the pre and post counselling scores of the school children. $\mathrm{P}<0.05$ was considered as statistically significant.

\section{Results}

\section{Disposition summary of type II diabetic patients}

Three hundred and five (305) school children were screened for Cardio-metabolic risk stratification and overweight as well as obese children were selected for life style interventions for risk reduction (Figure 1).

\section{Socio-demographic and anthropometric profile of school children}

Socio-demographic: A total of 305 children from classes $6^{\text {th }}$ to $10^{\text {th }}$ of MGM School, Nerul were screened for categorizing them into obese and overweight category. They fell under the age group of 10-16 years with an average age of 13.15. It included 176 males and 129 females.

Anthropometric: Patterned gradual increase in height was seen among school children beginning from classes $6^{\text {th }}$ to $10^{\text {th }}$ with an average height of $154.33+10.2 \mathrm{~cm}$. Similarly, considering the weight there is gradual increase in body weight starting from lower classes. However $10^{\text {th }}$ grade shows fall in weight taken from averages. The combined average BMI rounds to $18.76+2.2$.

\section{Categorization of students as per BMI into overweight and obese}

After calculating the BMI which is a considered a reliable tool for determining obesity, $10.16 \%$ (i.e 31) children were found to be overweight and 3.93\% (i.e 12) were obese out of the total 305 children. Rest of the children was under the normal BMI category (Table 1).

\section{Distribution of diabetes risk among obese and ove- rweight children}

Post categorization, depending on their age, waist circumference, physical activity and family history, the children were stratified into low, moderate and high diabetes risk categories. Only $1 \%$ of school children were found to be under low diabetes risk, $61.3 \%$ under moderate risk and $35.5 \%$ under high diabetes risk out of the 31 children categorized to be obese and overweight.

Among the 31 children with high BMI, were divided into two categories-obese and overweight. 22 fell under overweight category and 9 under obese category. Only 1 child in the overweight category fell under low diabetes risk. Maximum number of overweight children fell under moderate risk of diabetes $(68.2 \%)$. Distribution of obese children into moderate and high risk is almost equal with $44.4 \%$ and $55.5 \%$ respectively (Figure 2).

\section{Distribution of Cardiovascular Disease (CVD) risk among obese and overweight children}

Based on their BMI, systolic blood pressure, diastolic blood pressure, cardiac fitness and physical activity, the children were categorized into low, moderate and high CVD risk categories (scores $<5$ in low category, 6-10 under moderate category and $>11$ under high risk category) The highest score noted among school children was found to be 18 .

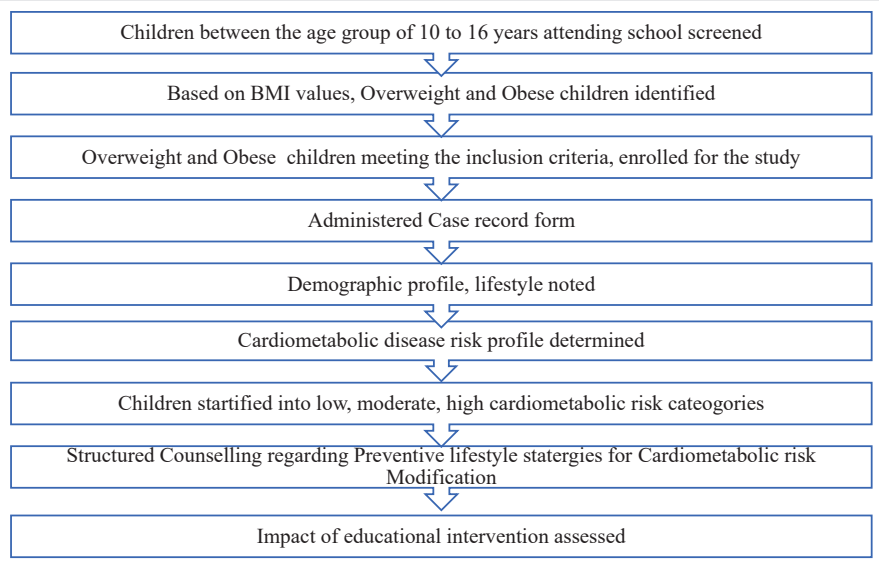

Figure 1: Disposition summary of Cardio-metabolic risk stratification and life style interventions for risk reduction among overweight and obese children.

Table 1: Categorization of Students as per BMI into Overweight and Obese.

\begin{tabular}{|c|c|c|c|c|c|c|c|}
\hline Class & $\begin{array}{c}\text { No of } \\
\text { Students }\end{array}$ & \multicolumn{2}{|c|}{ Normal (BMI<23) } & $\begin{array}{c}\text { Overweight (BMI: } \\
\text { 23-28) }\end{array}$ & \multicolumn{2}{|c|}{ Obese (BMl>28) } \\
\hline $\mathbf{( S t d )}$ & $\mathbf{( N )}$ & $\mathbf{( N )}$ & $\mathbf{( P e r c e n t a g e )}$ & $\mathbf{( N )}$ & $\mathbf{( P e r c e n t a g e )}$ & $\mathbf{( N )}$ & (Percentage) \\
\hline 10 & 70 & 66 & 94.28571 & 2 & 2.857143 & 2 & 2.857143 \\
\hline 9 & 59 & 43 & 72.88136 & 11 & 18.64407 & 5 & 8.474576 \\
\hline 8 & 51 & 42 & 82.35294 & 6 & 11.76471 & 3 & 5.882353 \\
\hline 7 & 61 & 54 & 88.52459 & 6 & 9.836066 & 1 & 1.639344 \\
\hline 6 & 64 & 57 & 89.0625 & 6 & 9.375 & 1 & 1.5625 \\
\hline Total & 305 & 262 & 85.90164 & 31 & 10.16393 & 12 & 3.934426 \\
\hline & & & & & & & 029 \\
\hline
\end{tabular}


Almost all obese children (88.9\%) i.e 8 out of 9 children had high CVD risk. The two children mentioned earlier had BMIs above the 95th percentile and fell under this category. 15 overweight children (68.2\%) fell under the high CVD risk category while 7 fell under moderate CVD risk (Figure 3).

\section{Profile of obese and overweight children}

Among the overweight children $72.7 \%$ had waist circumference ( $>+2 \mathrm{SD}$ ) compared to age matched controls whereas $100 \%$ children had waist circumference ( $>+2$ SD) in the obese group. Systolic and diastolic blood pressure $(>+2$ SD) was encountered among $4.5 \%$ of the overweight children compared to $11.1 \%$ in the obese group (Table 2).

\section{Lifestyle pattern among overweight and obese children}

Intake of fruits \& vegetable Intake /day (400-500 g) was noted among $27.3 \%$ children who were overweight as compared to $11.1 \%$ obese children. Salt restriction ( $<5 \mathrm{~g} /$ day) was noted among $\mathbf{2 7 . 3} \%$ belonging to overweight category as compared to $11.1 \%$ obese children. Saturated fat restriction $(<30 \%$ of total calories) was encountered in $27.3 \%$ overweight children as compared to $0 \%$ children who were obese. Physical activity less than 30 min was encountered in $9.1 \%$ school children who were overweight compared to $33.3 \%$ obese children (Table 3 ).

Impact of Structured Educational Intervention on Knowledge regarding cardio-metabolic risk modification among school children.

The school children's baseline knowledge on Preventive Strategies for Cardio-metabolic Risk modification was scored. Subsequently, the children were counseled based on WHO CVD Risk Reduction Guidelines and thereafter re-administered the same questionnaire to assess the impact of educational Intervention. Counseling resulted in a significant increase in knowledge regarding preventive Strategies for Cardiometabolic risk modification. Post Counseling the total score and score related to item: diet $(\mathrm{p}<0.05)$ improved significantly as compared to Pre-Counseling scores (Figure 4). Majority of the school children found the counseling to be useful, complete and balanced.

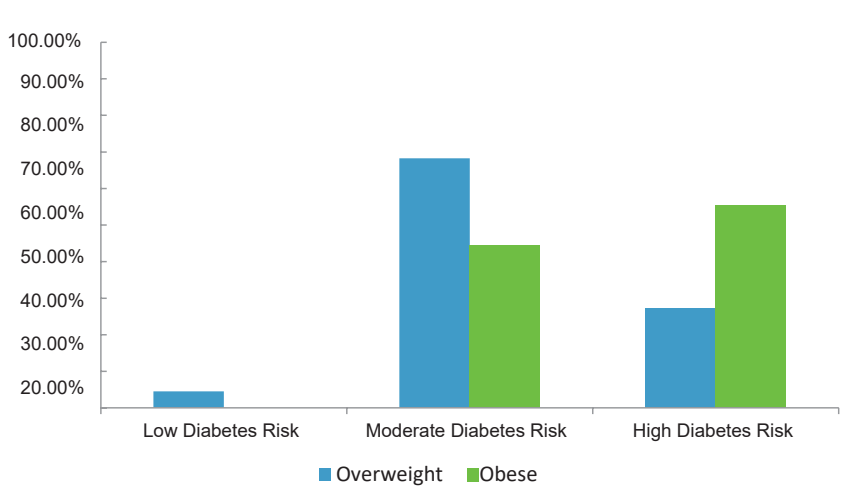

Figure 2: Distribution of Diabetes Risk among Obese and Overweight children.

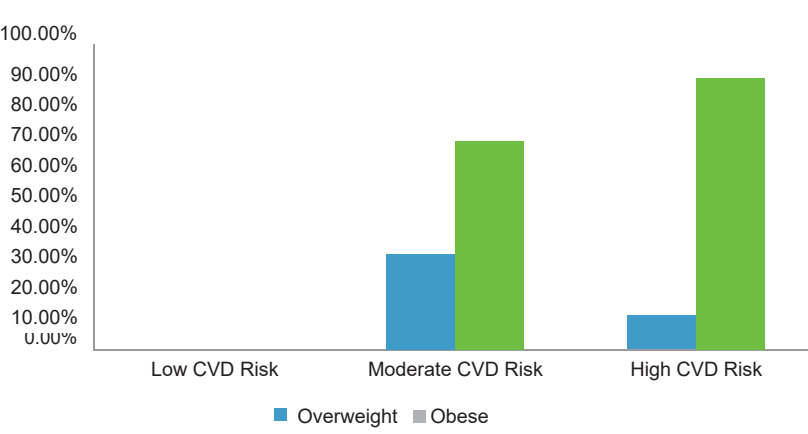

Figure 3: Cardiovascular disease Risk among Obese and Overweight children.

Table 2: Profile of Overweight and Obese Children.

\begin{tabular}{|c|c|c|c|c|}
\hline & \multicolumn{2}{|c|}{ Overweight (n=22) } & \multicolumn{2}{|c|}{ Obese $(n=9)$} \\
\hline & Number & Percentage & Number & Percentage \\
\hline \multicolumn{5}{|c|}{ Gender } \\
\hline Male $(\mathrm{N}=24)$ & 17 & $77.3 \%$ & 7 & $77.7 \%$ \\
\hline (Female $(\mathrm{N}=7)$ & 5 & $22.7 \%$ & 2 & $22.2 \%$ \\
\hline BMI & 22 & $71 \%$ & 9 & $29 \%$ \\
\hline \multicolumn{5}{|c|}{ Waist Circumference } \\
\hline More than + 1 SD & 6 & $27.3 \%$ & 0 & $0 \%$ \\
\hline More than +2 SD & 16 & $72.7 \%$ & 9 & $100 \%$ \\
\hline \multicolumn{5}{|c|}{ Systolic Blood Pressure } \\
\hline More than + 1 SD & 2 & $9.1 \%$ & 3 & $33.3 \%$ \\
\hline More than +2 SD & 1 & $4.5 \%$ & 1 & $11.1 \%$ \\
\hline \multicolumn{5}{|c|}{ Diastolic Blood Pressure } \\
\hline More than +1 SD & 0 & $0 \%$ & 0 & $0 \%$ \\
\hline More than +2 SD & 1 & $4.5 \%$ & 1 & $11.1 \%$ \\
\hline
\end{tabular}

Table 3: Lifestyle Pattern among Overweight and Obese Children.

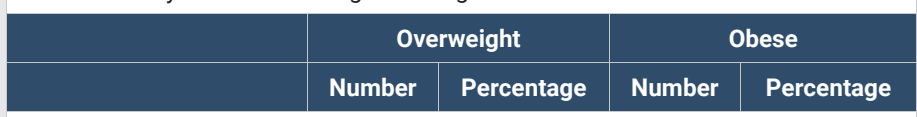

Dietary Pattern

Intake of fruits \& vegetable Intake /day (400-500 g )

\begin{tabular}{c|c|c|c|c|}
\hline Always & 6 & $27.3 \%$ & 1 & $11.1 \%$ \\
\hline Sometimes & 14 & $63.6 \%$ & 8 & $88.9 \%$ \\
\hline Never & 2 & $9.1 \%$ & 0 & $0 \%$ \\
\hline
\end{tabular}

Practice salt restriction $(<5 \mathrm{~g} /$ day $)$

\begin{tabular}{c|c|c|c|c|}
\hline Always & 6 & $27.3 \%$ & 1 & $11.1 \%$ \\
\hline Sometimes & 0 & $0 \%$ & 4 & $44.4 \%$ \\
\hline Never & 16 & $72.7 \%$ & 4 & $44.4 \%$ \\
\hline
\end{tabular}

Practice saturated fat restriction ( $<30 \%$ of total calories)

\begin{tabular}{c|c|c|c|c|}
\hline Always & 6 & $27.3 \%$ & 0 & $0 \%$ \\
\hline Sometimes & 13 & $59.1 \%$ & 4 & $44.4 \%$ \\
\hline Never & 3 & $13.6 \%$ & 5 & $55.6 \%$ \\
\hline
\end{tabular}

Physical Activity

\begin{tabular}{|c|c|c|c|c|}
\hline More than $60 \mathrm{~min}$ & 3 & $13.6 \%$ & 1 & $11.1 \%$ \\
\hline etween $30-60$ minutes & 17 & $77.3 \%$ & 5 & $55.6 \%$ \\
\hline $\begin{array}{c}\text { Less than } 30 \\
\text { minutes }\end{array}$ & 2 & $9.1 \%$ & 3 & $33.3 \%$ \\
\hline
\end{tabular}

Citation: Kamale S, Mohanty IR, Kamale V, Mohanty N, Mishra SD (2020) Cardio-metabolic risk stratification and life style interventions for risk reduction among overweight and obese school children. Open J Pediatr Child Health 5(1): 027-033. DOI: https://dx.doi.org/10.17352/ojpch.000027 


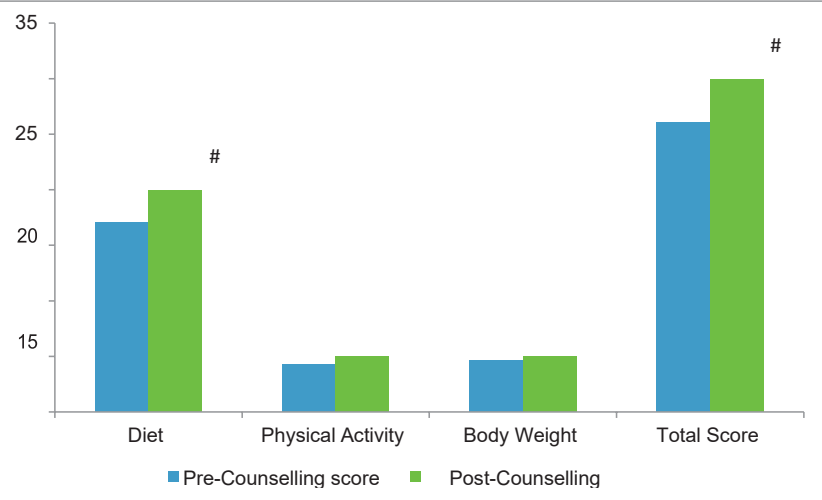

Figure 4: Impact of Counseling on Knowledge regarding cardio- metabolic risk modification among school children. \#P<0.05 Vs Pre-counselling scores.

\section{Discussion}

Childhood obesity is on the rise in India especially in the urban areas. Prevalence of obesity among school children in India varies between $5.74 \%$ to $8.82 \%$ [13,14]. Studies have reported that $21.4 \%$ boys and $18.5 \%$ girls are either obese or overweight in South India $[12,15]$. In the present study out of the 305 children who were screened $10.16 \%$ were overweight and $3.93 \%$ were obese. Studies have reported that in children above $5 \mathrm{yr}$, the prevalence of obesity varied between 2 to 8 per cent [10]. Overweight rates were around two times higher and seem to be more in northern and eastern India than in southern India. One study from Srinagar reported a high prevalence rate of 25 per cent, probably due to the smaller numbers studied and being from affluent families [16]. The least prevalence of obesity was reported from Nagaland (2.3\%) and the maximum from New Delhi (29\%) [14-16].

\section{Cardio-metabolic risk among obese and overweight children}

Childhood obesity strongly correlates with insulin resistance and type-2 diabetes. Moreover, severe obesity occurs in a majority of diabetic youth, and the emergence of prediabetes and type-2 diabetes in children closely correlated in time with the childhood obesity epidemic. A direct pathological association of obesity with cardiovascular disease may be mediated by increased preload and vascular damage. When combined with ectopic fat accumulation in the myocardium, increased ventricular stiffness leads to vascular dysfunction, hypertension and left ventricular hypertrophy. Independently, obesity-associated insulin and leptin resistance also promote inflammation and endothelial dysfunction which increases arterial stiffness, susceptibility to plaque formation and accelerated atherosclerosis $[17,18]$. The myriad of cardio metabolic complications associated with diabetes will make the disease a public health problem in the future.

In the present study the cardio metabolic risk among school children who were overweight and obese was assessed using validated scales. Diabetes prediction tool like the Indian Diabetes Risk score, a simple user friendly tool modeled by Mohan, et al. from their Chennai Urban Rural Epidemiology Study cohort was used in the present study. The IDRS has a sensitivity of $72.5 \%$ and a specificity of $60.1 \%$ and is based on the largest population based study in India [19]. Similarly a Healthy Heart Score for Assessment of CVD risk which uses established risk factors that can be easily assessed in a school environment was used. It was independent of both age and sex and acknowledged both number and severity of CVD Risk factors [20].

With help of the different percentile charts from Indian Academy of Pediatrics (IAP) including the Revised IAP Growth charts for height, weight and BMI [10], SBP and DBP percentiles by age and gender [21] and waist circumference percentiles for Indian children 3-16 years of age (Kuriyan, et al. [22]), the children were classified into low, moderate and high CVD and Diabetic risk. $80 \%$ had waist circumferences $>95$ th percentile, $22.5 \%$ had SBP >85th percentile, $28 \%$ had BMI >95th percentile. $61.3 \%$ children had moderate risk and $35.5 \%$ had high risk of diabetes and maximum number of children who fell under moderate risk of diabetes $(68.2 \%)$ were overweight. Distribution of obese children into moderate and high risk was found to be $44.4 \%$ and $55.5 \%$ respectively. For CVD Risk, $25.8 \%$ children presented with moderate risk and $74.2 \%$ with high risk while $0 \%$ presented with low risk. It was observed that $31.2 \%$ of overweight had moderate and $68.2 \%$ had high risk of CVD; $11.1 \%$ of obese had moderate and $88.9 \%$ had high risk of CVD. Thus, $35.5 \%$ children who were overweight or obese had high diabetes risk and 74.2\% children had high CVD risk in their adulthood. Studies show that uncontrolled body weight present as major culprits in development of diabetes and cardiovascular diseases like atherosclerosis, myocardial infarction and stroke in the future [9]. Therefore, efforts should be made to keep body weight under permissible limits.

\section{Clinical profile and life style pattern among obese and overweight children}

Among the overweight children $72.7 \%$ had waist circumference $(>+2 \mathrm{SD})$ compared to age matched controls whereas $100 \%$ children had waist circumference $(>+2$ SD) in the obese group. Systolic and diastolic blood pressure $(>+2$ SD) was encountered among $4.5 \%$ the overweight children compared to $11.1 \%$ in the obese group. Thus, central obesity and hypertension are important determinants of increased cardio-metabolic risk and therefore need to be addressed to reduce the burden of diabetes and cardiovascular disease related morbidity and mortality.

Looking at the lifestyle pattern among obese and overweight children abstinence of intake of fruits \& vegetable Intake /day (400-500 g) was noted in $9.1 \%$ children who were overweight. Abstinence of Salt restriction ( $<5 \mathrm{~g} /$ day) was noted among 72.7 $\%$ belonging to overweight category as compared to $44.4 \%$ obese children. Not practicing saturated fat restriction $(<30$ $\%$ of total calories) was encountered in $13.6 \%$ overweight children as compared to $55.6 \%$ children who were obese. Physical activity less than 30 min was encountered in $9.1 \%$ school children who were overweight compared to $33.3 \%$ obese children. This shows that the children were lacking in baseline knowledge regarding lifestyle habits and needed guidance. 


\section{Structured educational Intervention for cardiometabolic risk reduction}

Overweight and obese children were administered structured counseling for CVD and Diabetes risk reduction. Also, the impact of structured counseling on the knowledge regarding cardiometabolic risk reduction was assessed.

The children who were obese and overweight were counseled based on WHO CVD Risk Reduction Guidelines and thereafter re-administered the same questionnaire to assess the impact of structured counseling. Educational Intervention resulted in a significant increase in knowledge regarding preventive Strategies for Cardio-metabolic risk modification. Post Counseling the total score and score related to item: diet $(\mathrm{p}<0.05)$ increased significantly as compared to pre-Counseling scores. Majority of the school children found the counseling to be useful, complete and balanced.

Current clinical guidelines for childhood obesity are lifestyle, dietary and exercise interventions for prevention and management of obesity and using BMI to measure the success of the intervention along with other approaches like pharmacotherapy and bariatric surgery [23]. However, several studies adhere to the most common interventions for childhood obesity that include eating a healthy diet, increasing moderateto-vigorous physical activity and reducing sedentary activities [24].

In another study which focused mainly on exercise programs in treating childhood obesity, procured that regular exercise decreases BMI, Blood pressure, waist circumference and LDL-C which are also causes of metabolic syndromes. Regular short-term (10 weeks) exercise program had a positive influence in prevention and treatment of obesity such as reducing body weight and insulin resistance preventing type2-DM. Long-term exercise programs, one lasting 12 weeks, demonstrated improvements in endothelial function on adult individuals with diabetes and impaired glucose tolerance and short-term programs (4 weeks) improve arterial function in individuals with pre or mild hypertension [25].

Results of the present study have provided baseline information on the CVD risk profile, diabetes risk profile and life style intervention for obese children. The purpose of emphasizing the recommendations elaborated in the WHO guidelines through structured counseling is to motivate and assist cardio metabolic high-risk individuals to lower their cardiometabolic risk by: making healthy food choice, being physically active, reducing body mass index, lowering blood pressure, lowering blood cholesterol, controlling glycaemia, restricting salt intake.

Consumption of easily available savory fast foods sold at affordable prices and ignorance of parents towards the child's eating habits are some the major etiological factors of obesity. Similarly, replacement of outdoor sports and physical activity by digital gaming platforms, having a sedentary lifestyle further amplifies the risk of becoming obese and developing cardiovascular or metabolic diseases in adulthood [26].
Childhood obesity is on the rise. Obesity leads to many complications like type 2 diabetes mellitus and cardiovascular diseases, stroke, etc. The sample size used in the present study is a limitation and also the fact that long term follow up to determine how the educational intervention translates into clinical benefits does not fit in the scope of the study. Although the preliminary results are interesting and meaningful; this issue warrants intensive studies of the prevalence of cardiometabolic risk among overweight and obese children and structured intervention for risk reduction.

\section{Conclusion}

Healthy heart score for assessment of CVD risk and IDRS predicts that around $74.2 \%$ and $35.5 \%$ of obese and overweight children have High Risk of developing cardiovascular diseases and diabetes respectively in adulthood. Counseling resulted in a significant increase in knowledge \{related to weight control, salt intake, saturated fat restriction, physical activity, maintaining blood pressure\} regarding preventive strategies for CVD and Diabetes Risk modification. Early identification of cardio metabolic risks in children with obesity is affirmed to prevent long-term complications.

\section{Acknowledgement}

The Study is an Indian Council of Medical Research short term studentship (ICMR STS -2019-04777) Project.

\section{References}

1. Mahajan S, Kaur P (2017) Diabetes mellitus type II in school children: Risk evaluation and its genetic correlation. Int $\mathrm{J}$ Oral Health Sci 7: 4-9. Link: https://bit.ly/3eFfZOr

2. Hedley AA, Ogden CL, Johnson CL, Carroll MD, Curtin LR, et al. (2004) Prevalence of overweight and obesity among US children, adolescents, and adults, 1999-2002. Journal of the American Medical Association 291: 2847 2850. Link: https://bit.ly/3fKfMeg

3. Ramachandran A, Snehalatha C, Yamuna A, Murugesan N, Narayan VM, et al. (2007) Insulin Resistance and Clustering of Cardiometabolic Risk Factors in Urban Teenagers in Southern India. Diabetes Care 30: 1828-1833. Link: https://bit.ly/3h7kYJh

4. Kate ER, Darren ER, Heather A (2007) Determining cardiovascular disease risk in elementary school children: Developing a healthy heart score. J Sports Sci Med 6: 142-148. Link: https://bit.ly/2OBIYZP

5. Raitakari OT, Juonala M, Kahonen M, Taittonen L, Laitinen T, et al. (2003) Cardiovascular risk factors in childhood and carotid artery intima-media thickness in adulthood: the Cardiovascular Risk in Young Finns Study Journal of the American Medical Association 290: 2277- 2283. Link: https://bit.ly/2ZFk40S

6. Strauss RS, Pollack HA (2001) Epidemic increase in childhood overweight, 1986-1998. Journal of the American Medical Association 286: 2845-2848. Link: https://bit.ly/2Clk1hL

7. Claire MN, Ghattu VK, Alicja RR, Owen CG, Veena SR, et al. (2012) Cardiometabolic Risk Markers in Indian Children: Comparison with UK Indian and White European Children. PLoS One 7: e36236. Link: https://bit.ly/3fKcHLe

8. Hayman LL, Williams CL, Daniels SR, Steinberger J, Paridon S, et al. (2004) Cardiovascular Health Promotion in Schools. A statement from the committee on Atherosclerosis, Hypertension and Obesity in Youth (AHOY). Circulation 110: 2266-2275. Link: https://bit.ly/2Clv1vA 
9. Pawar S, Choksey A, Jain S, Surude RG, Rathi PM (2016) Prevalence of Overweight and Obesity in 4 Schools of South Mumbai. J Clin Diagn Res 10: oc010C02. Link: https://bit.ly/3fD9b5f

10. Khadilkar VV, Khadilkar AV, Borade AB, Chiplonkar SA (2012) Body mass index cut-offs for screening for childhood overweight and obesity in Indian children. Indian Paediatr 49: 29-34. Link: https://bit.ly/3943j2e

11. Ranjani H, Mehreen TS, Pradeepa R, Mohan Anjana R, Garg R, et al. (2016) Epidemiology of childhood overweight \& obesity in India: A systematic review. Indian J Med Res 143: 160-174. Link: https://bit.ly/2WvIQyh

12. Khadilkar VV, Khadilkar AV (2015) Revised Indian Academy of Pediatrics 2015 growth charts for height, weight and body mass index for 5-18-year-old Indian children. Indian J Endocrinol Metab 19: 470- 476. Link: https://bit.ly/3jbVQD5

13. Ahmad Q, Ahmad CB, Mushtaq Ahmad S (2010) Childhood Obesity. Indian J Endocrinol Metab 14: 19-25. Link: https://bit.ly/2WqfMs0

14. Vedavathi S, Jayashree R, Rafi M (2003) Prevalence of overweight \& obesity in Chennai in 1981 \& 1998. Indian Pediatr 40: 775-779. Link: https://bit.ly/3jfk5QE

15. Kapil U, Singh P, Pathak P, Dwivedi SN, Bhasin S (2002) Prevalence of obesity among Affluent adolescent school children in Delhi. Indian Pediatr 39: 449452. Link: https://bit.ly/3fFakt1

16. Kumar S, Mahabalaraju DK, Anuroopa MS (2007) Prevalence of obesity and its Influencing Factor among Affluent School children of Davangere City. Indian Journal of Community Medicine 32: 15-17. Link: https://bit.ly/397NF67

17. Dhingra R, Sharma A, Azad AM (2011) Vulnerability for life style disorders among affluent primary school children of Srinagar, Jammu and Kashmir, India. Stud Home Com Sci 5: 147-155. Link: https://bit.ly/3jcF9Hr
18. Chung ST, Onuzuruike AU, Magge SN (2018) Cardio-metabolic risk in obese children. Ann N Y Acad Sci 1411: 166-183. Link: https://bit.ly/3h3oS5Q

19. Twig G, Yaniv G, Levine H, Leiba A, Goldberger N,et al. (2016) Body-Mass Index in 2.3 Million Adolescents and Cardiovascular Death in Adulthood. N Engl J Med 374: 2430-2440. Link: https://bit.ly/39hukQ9

20. Mohan V, Deepa R, Deepa M, Somannavar S, Datta M, et al. (2005) A simplified Indian Diabetic Risk Score for screening of undiagnosed diabetic subjects. J Assoc Physicians India 53: 759-763. Link: https://bit.ly/2Clenfz

21. Narang R, Saxena A, Ramakrishnan S, Dwivedi SN, Bagga A (2015) Oscillometric blood pressure in Indian school children: Simplified percentile tables and charts. Indian Pediatr 52: 939-945. Link: https://bit.ly/2CdvFLL

22. Kuriyan R, Thomas T, P Lokesh D, Sheth Nr, Mahendra A, et al. (2010) Waist circumference and waist for height percentiles in urban South Indian children ages 3-16 years. Indian Pediatrics 48: 765-771. Link: https://bit.ly/2OAVqrC

23. Lau DC, Douketis JD, Morrison KM, Hramiak IM, Sharma AM, et al. (2006) 2006 Canadian clinical practice guidelines on the management and prevention of obesity in adults and children. CMAJ 176: 1310. Link: https://bit.ly/30fOHuw

24. Cote AT, Harris KC, Sandor GGS, Devlin AM (2013) Childhood obesity and cardiovascular dysfunction. JACC 62: 1309-1319. Link: https://bit.ly/20whrbh

25. Lee YH, Song YW, Kim HS, Lee SY, Jeong HS, et al. (2010) The effects of an exercise program on anthropometric, metabolic, and cardiovascular parameters in obese children. Korean Circ J 40: 179-184. Link: https://bit.ly/3963RVg

26. Anjello M, Rajan J, Shrinivasan R (2018) Arockiam Thaddeus Childhood obesity: The Indian Scenario compared with worldwide; Curre Res Diabetes and Obes J 5: 555672. Link: https://bit.ly/32tZXEn

\section{Discover a bigger Impact and Visibility of your article publication with}

\section{Peertechz Publications}

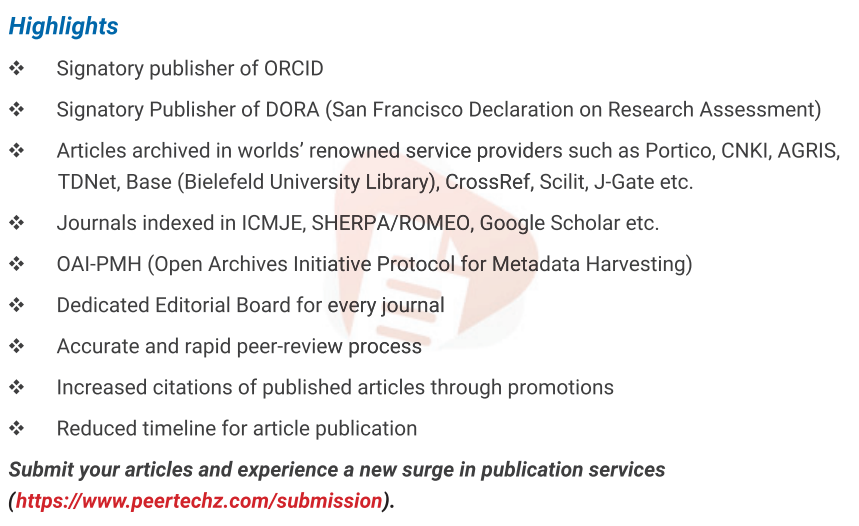

Peertechz journals wishes everlasting success in your every endeavours.

Copyright: @ 2020 Kamale S, et al. This is an open-access article distributed under the terms of the Creative Commons Attribution License, which permits unrestricted use, distribution, and reproduction in any medium, provided the original author and source are credited.

Citation: Kamale S, Mohanty IR, Kamale V, Mohanty N, Mishra SD (2020) Cardio-metabolic risk stratification and life style interventions for risk reduction among overweight and obese school children. Open J Pediatr Child Health 5(1): 027-033. DOI: https://dx.doi.org/10.17352/ojpch.000027 